Case Report

\title{
Resolving a Multi-Generational Neuromuscular Mystery in a Family Presenting with a Variable Scapuloperoneal Syndrome in a c.464G $>$ A, p.Arg155His VCP Mutation
}

\author{
Nivedita U. Jerath \\ AdventHealth Orlando, Neuromuscular Division, 1573 West Fairbanks, Winter Park, FL 32789, USA \\ Correspondence should be addressed to Nivedita U. Jerath; njerath@post.harvard.edu
}

Received 23 April 2019; Revised 26 July 2019; Accepted 31 August 2019; Published 9 October 2019

Academic Editor: Philip D. Cotter

Copyright (C) 2019 Nivedita U. Jerath. This is an open access article distributed under the Creative Commons Attribution License, which permits unrestricted use, distribution, and reproduction in any medium, provided the original work is properly cited.

\begin{abstract}
Valosin containing protein (VCP) mutations have been reported to present with a high degree of variability and can be present in patients even if they may have an initial normal work up. A 55-year-old woman was labeled as "normal" and "pain medication seeking" after an unrevealing work up of clinical, laboratory, electrodiagnostic, radiographic, pathologic, and genetic testing. She continued to present with chronic neck pain, and had variable features of scapuloperoneal atrophy, which was also seen in her family. The patient and her family were found to have a known pathogenic c. $464 \mathrm{G}>\mathrm{A}$, p. Arg $155 \mathrm{His}\left(\mathrm{R}^{155} \mathrm{H}\right)$ mutation in the $V C P$ gene. Despite traditional thinking of attempting to localize neurological syndromes, VCP mutations are difficult to localize as they can present with significant clinical heterogeneity including a scapuloperoneal syndrome with variable neuropathic and myopathic features.
\end{abstract}

\section{Introduction}

The valsoin-containing protein $(V C P)$ can manifest variable clinical phenotypes due to its regulation of several distinct cellular processes [1]. It has even been called a "jack of all trades" in neuro and myodegeneration [2]. Although previously VCP mutations were known to cause hereditary inclusion body myopathy (IBM), Paget's disease of the bone (PDB), and frontotemporal dementia (FTD), collectively known as IBMFTD [1], there are now reported cases of familial amyotrophic lateral sclerosis (ALS), hereditary spastic paraplegia (HSP), parkinsonism, and Charcot-Marie-Tooth Type 2 disease [3], thus confirming that $V C P$ mutations are multisystem proteinopathies (MSP) [4]. Although there is such significant variability in $V C P$ mutations and clinical presentations $[5,6]$, the disease is inherited in an autosomal dominant fashion.

\section{Case Report}

The proband is a 55 year old Caucasian woman of Cornelius decent who was the product of a normal pregnancy and delivery. She reached her milestones on time. As a child, she was a fast runner for short distances, but could not run long distances or jump hurdles. She could ride a bike, but she could not roller skate. She could not walk on a log over a stream; she was noted to be very clumsy and had trouble with balance. She was unable to wear high heels and would have multiple falls due to weak ankles.

She would work every day but would present frequently to the neurology clinic due to neck and shoulder pain for 8 years. Prior work up resulted in a normal examination as well as the following normal work up: creatinine kinase, electrodiagnostic testing, magnetic resonance imaging of the brain, lumbar spine, cervical spine, and muscle biopsy of the left deltoid.

In her 50's, her symptoms progressed, and she was working with difficulty. She could not climb stairs or open jars. She could not wash her hair without support, and she was unable to lift heavy objects over her head. She denied any paresthesias or numbness. She noticed some muscle twitching around her eye, triceps, and cheek. She was constipated, and developed intermittent fecal and urinary incontinence. She would also get painful cramps at night.

Upon neurological examination, she presented with slanted shoulders (Figure 1(a)), and asymmetric high arches and hammer toes on the left more than the right (Figure 1(b)). 


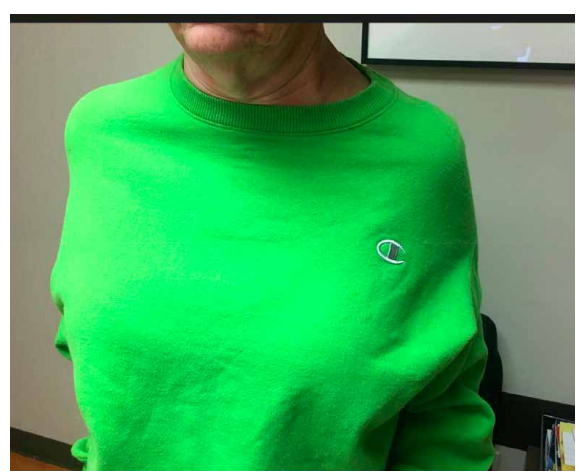

(a)

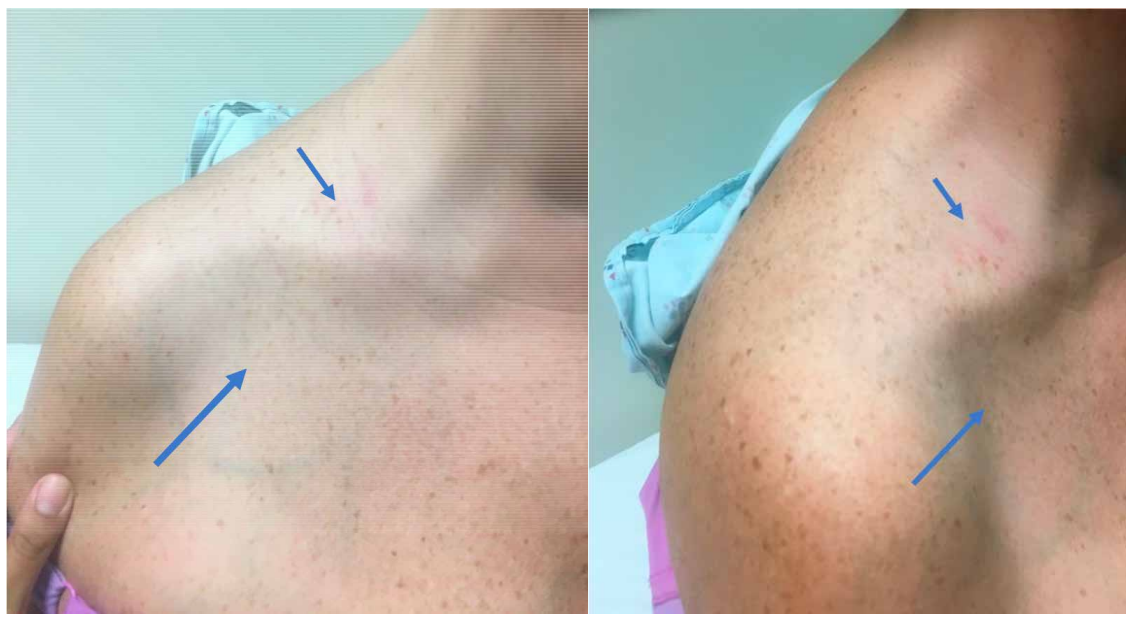

(c)

FIGURE 1: Slanted shoulders seen in the proband (a); asymmetric pes cavus in left foot (b); and trapezius and pectoralis atrophy seen in the proband (arrows) (c).

Strength examination (MRC scale) demonstrated trapezius and pectoralis atrophy in the area of her neck pain and weakness $(\mathrm{R} / \mathrm{L})$ 0/0 (Figure 1(c)). She was unable to raise her arms greater than 90 degrees over her head. She needed to lean forward to rise from a chair. Vibratory sense, joint position sense, and pinprick were decreased distally in the lower extremities. Deep tendon reflexes were normal and there was no tremor. Cerebellar testing was normal. She had a mildly positive Romberg sign with swaying. Gait was wide-based and she was unable to stand on her toes or heels. Cranial nerve examination and memory testing were normal. There were no fasciculations or upper motor neuron signs on exam.

Repeat laboratory testing included a normal creatine kinase, thyroid stimulating hormone, copper, methylmalonic acid, sedimentation rate, and a normal alkaline phosphatase level. She had a normal sleep study, normal renal ultrasound, and mildly abnormal cardiac stress test with mild ischemia of the anterior cardiac wall. She had a normal pulmonary function test at age 58.

\section{Electrodiagnostic Testing}

Her electrodiagnostic examination changed over time. At age 54, her electrodiagnostic testing was reportedly normal. At age 58, her repeat testing showed an axonal motor neuropathy,

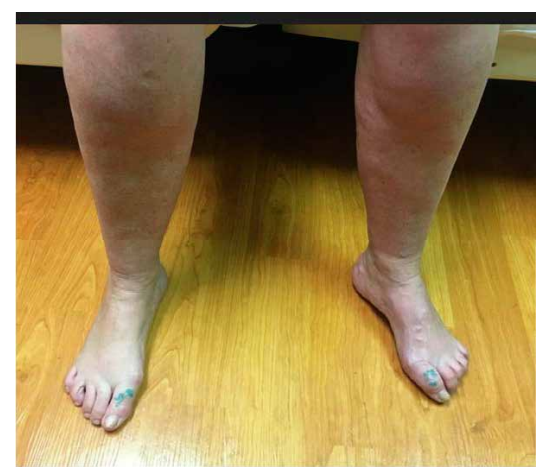

(b) neurogenic potentials (large amplitude motor unit potentials with reduce recruitment) in the tibialis anterior bilaterally. Bilateral peroneal motor responses had a reduced amplitude; left peroneal motor response had a prolonged distal motor latency. Nerve conduction velocities were normal except in the right median motor response was mildly slow with a sensory nerve conduction velocity of 42 meters per second at the wrist suggesting a possible superimposed carpal tunnel syndrome. The ulnar, radial, and bilateral sural sensory responses were normal.

\section{Muscle Biopsy}

Muscle biopsy of the left deltoid done at age 54 was reportedly normal upon repeated discussions; after genetic testing results were positive, the muscle biopsy reading changed slightly with the recognition of a rare atrophic motor unit and a regenerating fiber (Figure 2(a)). The muscle biopsy showed normal fiber type distribution using immunoperoxidase stains for slow and fast myosin heavy chains. There were no target fibers, inflammation, necrosis, regeneration, endomysial fibrosis, inclusion bodies, rimmed vacuoles, or ragged-red fibers. The older brother's muscle biopsy showed angulated atrophic fibers, type 1 and type II group atrophy (Figure 2(b)). 

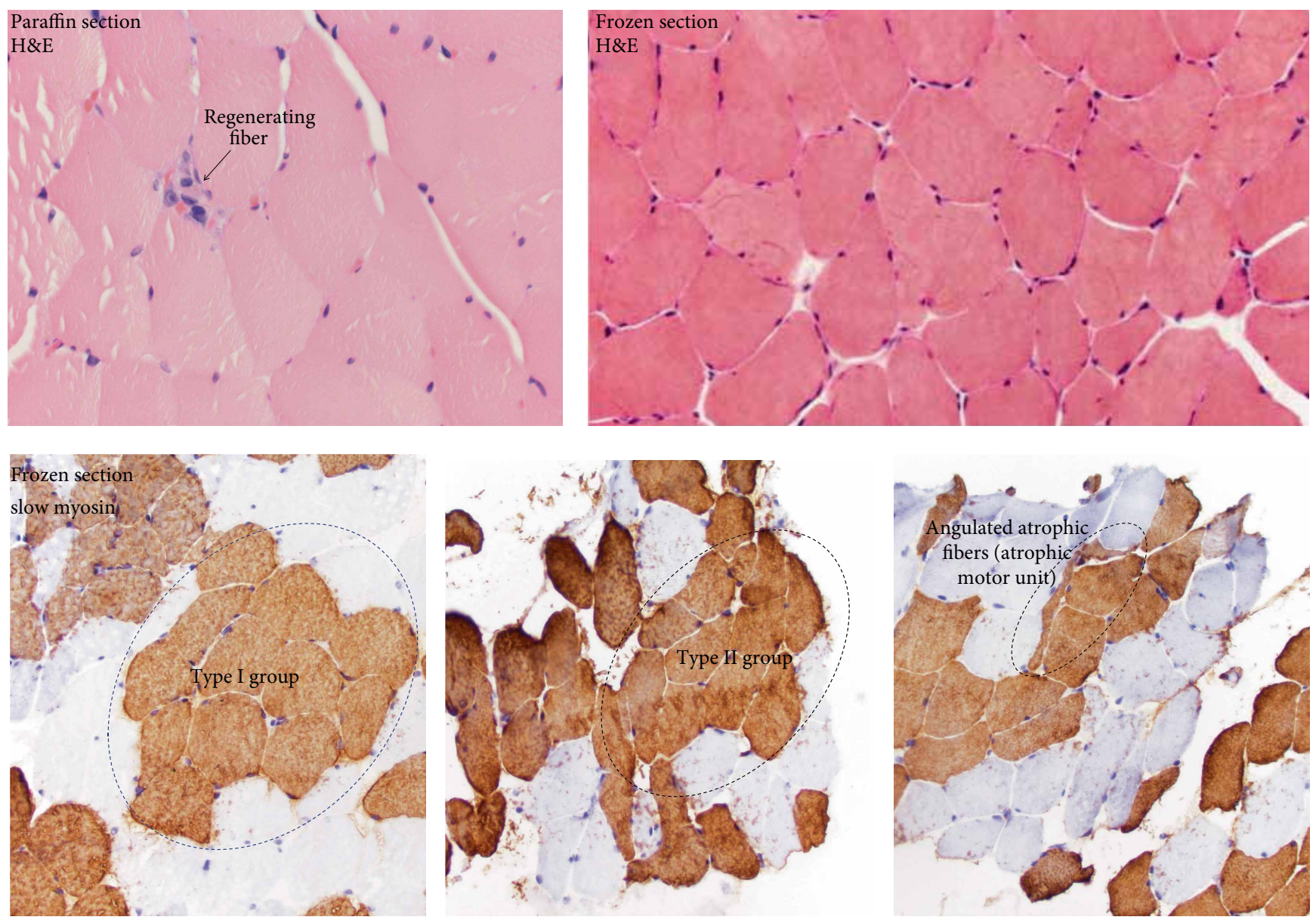

(a)

Figure 2: Continued.

\section{Family History}

Further investigation of the family history revealed a strong desire for an answer over multiple generations (Figure 3(a)). There was also a very complicated pedigree with variable features (Figure 4). Her paternal grandmother had scapuloperoneal weakness with an onset at age 50 (Figure 3(b)). A summary of the family history revealed variable features in almost every family member except for the autosomal dominant scapuloperoneal weakness (Table 1).

\section{Genetic Testing}

For many generations, extensive investigations were performed at multiple institutions revealing that SMA, FSHD, $S O D 1$, and C9orf72 testing was negative. Limb girdle muscular dystrophy testing revealed a DYSF (c.3268C >T, p.R1090C) variant for an autosomal recessive condition. Research exome sequencing of the proband's older brother revealed multiple variants of uncertain significance and was still being analyzed when commercial genetic testing panel in the proband and results revealed a pathogenic VCP mutation c. $464 \mathrm{~g}>\mathrm{a}$, p.
$\operatorname{Arg} 155$ His $\left(\mathrm{R}^{155} \mathrm{H}\right)$ [7-12]. This segregated appropriately in all affected family members.

\section{Discussion}

The proband and the family's case presented above is not straightforward clinically and adds to the diagnostic challenge that a VCP mutation can produce.

The most important diagnostic challenge in this case was that diagnostic investigations were normal in the proband initially; the electrodiagnostic testing changed over time (described previously [1]) and the pathological evaluation changed after the genetic testing came back positive. Exome sequencing was unrevealing and additional family members could not be obtained easily as presentations in family members were variable and inconsistent. The proband struggled for many years due to the difficulty in obtaining a diagnosis; this difficulty has been described to occur frequently in $V C P$ mutations [13].

Another diagnostic challenge was obtaining the family pedigree in a family that had difficult-to-localize neurological evaluations. Despite the scapuloperoneal syndrome seen in every affected family member, the other investigations 

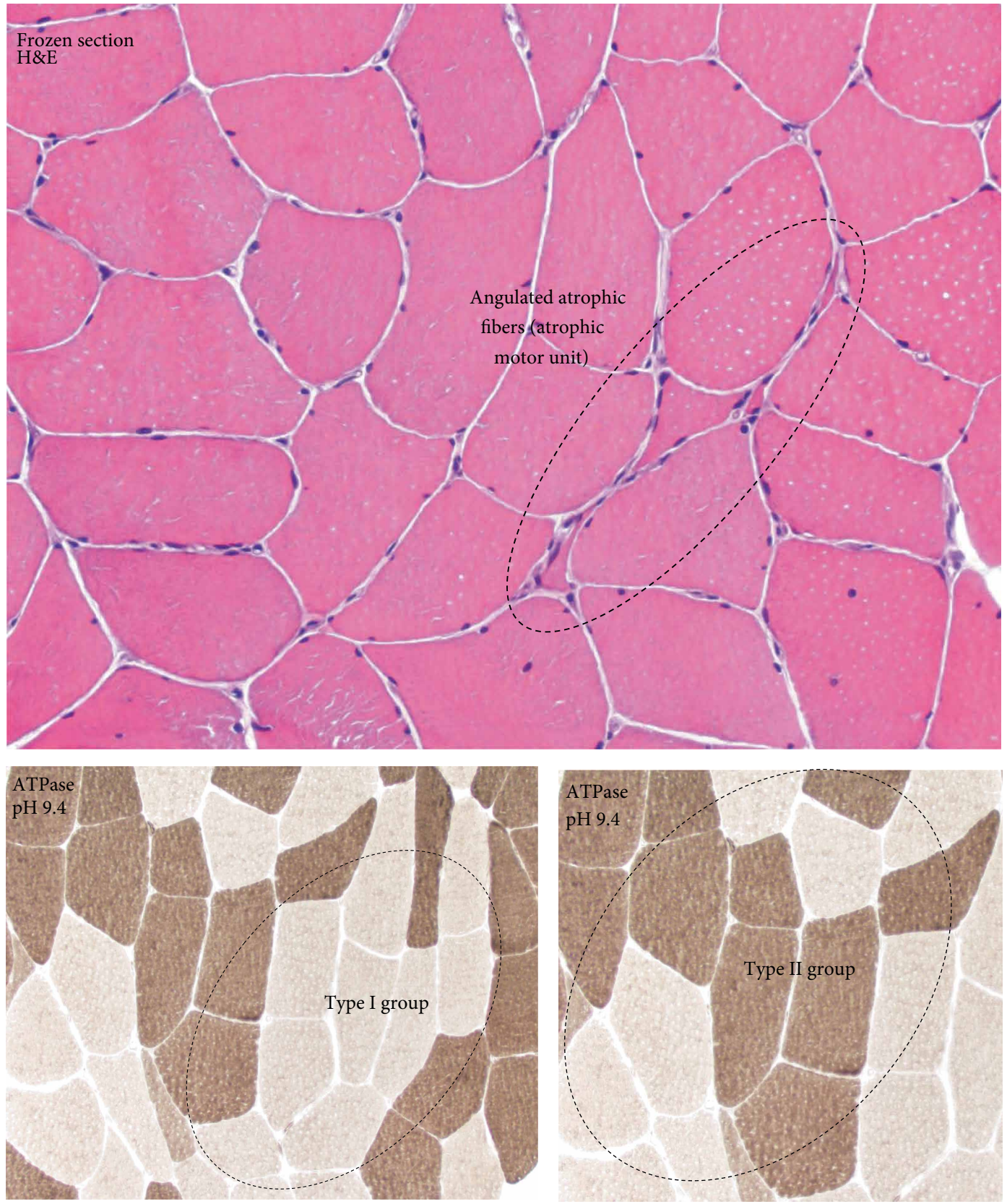

(b)

FIgURE 2: Muscle biopsy of the left deltoid.

including electrodiagnostic and muscle biopsy investigations were variable ranging from mixed neuropathic and myopathic features. This has been reported previously with a study on the $\mathrm{R}^{155} \mathrm{H}$ VCP mutation showing both myopathic and neurogenic features on EMG [14]. The study also suggested that $60 \%$ of muscle biopsies showed nonspecific myopathic changes and did not have to show inclusion body myopathy [14]. There was a large variability in the creatinine kinase level as well as a large interfamilial and intrafamilial variation in patients with valosin containing protein mutations similar to our family [14]. It seemed that the women had milder later onset symptoms compared to the men; this reasons for this are uncertain.
The resolution of this family's case reflects a new generation of diagnosing neuromuscular diseases; in the setting of a positive family history, neurologists should have a lower threshold to obtain genetic testing in the appropriate clinical context.

As VCP mutations are presenting with more and more varied neurological presentations, the clinical spectrum continues to expand (Figure 5). The scapuloperoneal syndrome itself adds to the clinical spectrum of VCP disease (Figure 5). A similar clinical presentation of a scapuloperoneal syndrome with mixed neuropathic and myopathic features was illustrated in a previous case report [1]. 


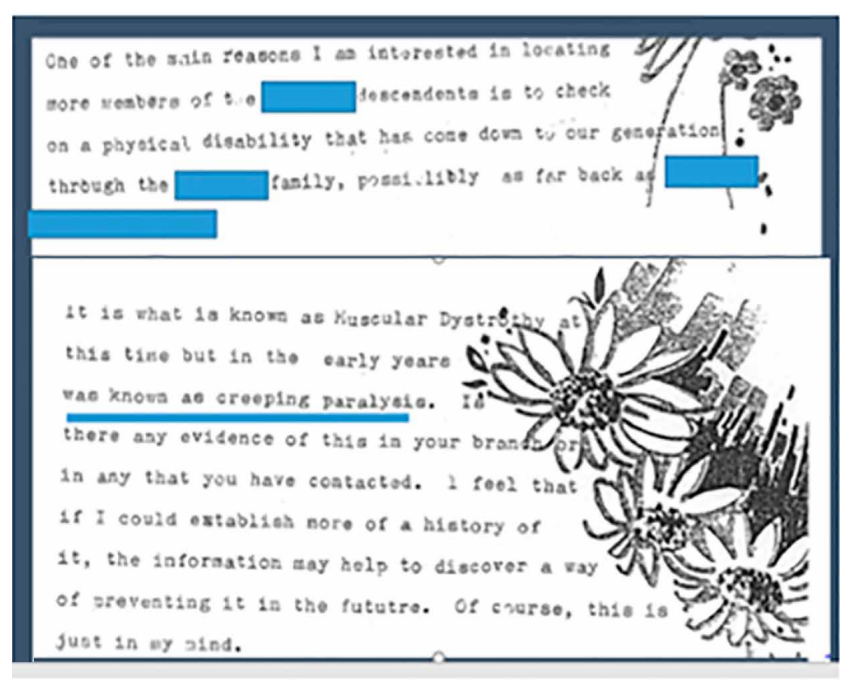

(a)

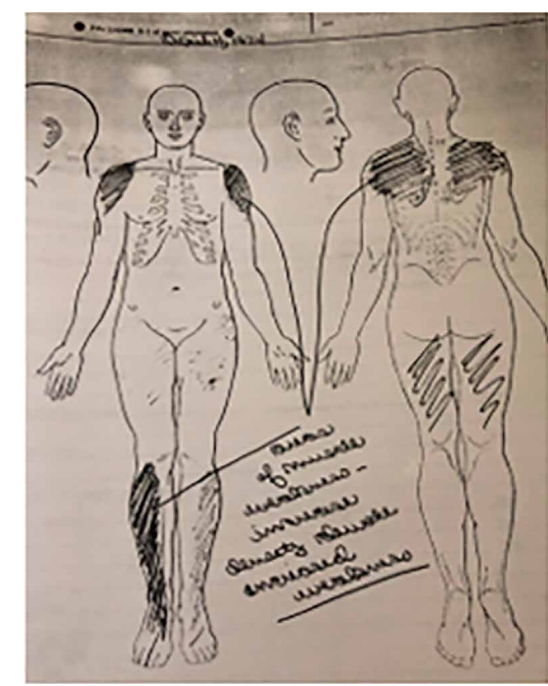

(b)

FIGURE 3: 1978 letter from grandmother describing "creeping paralysis" (a) and grandmother's exam shaded in at University of Iowa in 1974 depicting a "scapuloperoneal syndrome" (b).

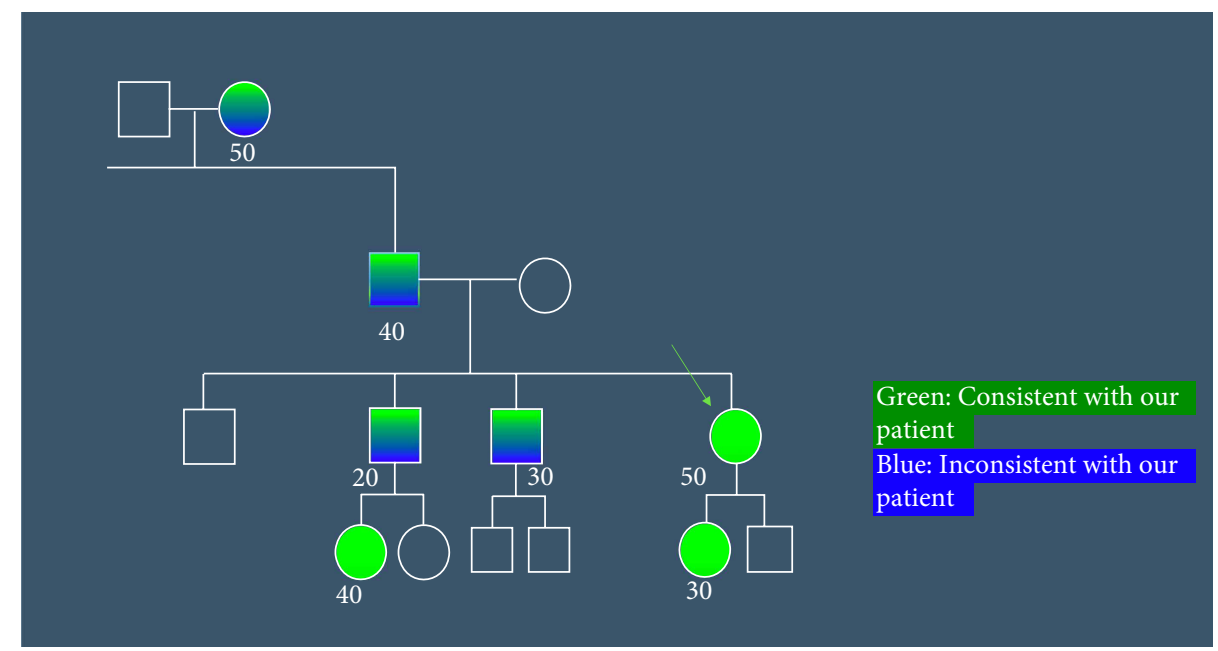

FIGURE 4: Family pedigree with features consistent and inconsistent with our patient.

Although the homozygous $\mathrm{R}^{155} \mathrm{H} / \mathrm{R}^{155} \mathrm{H}$ mouse model exhibits weakness, myopathic changes on electromyography, accelerated VCP disease pathology, Paget disease of the bone, and survival time of less than 21 days, the human manifestations of an individual heterozygous for the $\mathrm{R}^{155} \mathrm{H}$ pathologic gene mutation can present in numerous ways (Figure 5). The reason for this variability could be due to the multiple functions of the VCP gene, damaged mitochondria $[10,15]$, and possibly due to variable penetrance.

This case reflects the new term of multi-system proteinopathies [4]. VCP mutations can be considered the jack of all trades of neuromuscular medicine-a highly variable mutation that can present with both myopathic and neuropathic weakness including neck pain. When asked to localize in neurology, one may have a hard time figuring out the localization of a VCP mutation given its effect on multiple neurological process and its change in diagnostic evaluations over time.

\section{Ethical Approval}

The author confirms that she has read the Journal's position on issues involved in ethical publication and affirm that this report is consistent with those guidelines. Informed consent was obtained from all individuals reported in this study.

\section{Conflicts of Interest}

The author declares that he has no conflicts of interest.

\section{Acknowledgments}

The author would like to thank the patient and her family for their continued support. She would like to thank Invitae Genetics, Alnylam Pharmaceuticals, the Muscular Dystrophy Association, the University of Iowa Department of Neurology 
TABLE 1: Summary of the family history.

\begin{tabular}{|c|c|c|c|c|c|c|c|c|c|}
\hline Family member & $\begin{array}{l}\text { Scapulopero- } \\
\text { neal syndrome, } \\
\text { age of onset } \\
\text { of significant } \\
\text { symptoms }\end{array}$ & Pes Cavus & Reflexes & Dyspnea & $\begin{array}{l}\text { Inconti- } \\
\text { nence }\end{array}$ & $\begin{array}{c}\text { CK } \\
\text { elevated }\end{array}$ & $\begin{array}{c}\text { EMG abnor- } \\
\text { mal }\end{array}$ & Muscle biopsy & Dementia \\
\hline Grandmother & 50 & Present & $\begin{array}{l}\text { Brisk, ankle } \\
\text { reflex absent }\end{array}$ & & & & Neurogenic & $\begin{array}{c}\text { Neuropathic } \\
\text { and Myopathic }\end{array}$ & $\begin{array}{c}\text { Present at old } \\
\text { age per family } \\
\text { but not formally } \\
\text { tested }\end{array}$ \\
\hline Father & 40 & & Absent & & & & Neurogenic & Neuropathic & \\
\hline $\begin{array}{l}\text { Proband } \\
\text { (confirmed by } \\
\text { genetic testing) }\end{array}$ & 50 & Present & Normal & & Present & & Neurogenic & $\begin{array}{l}\text { "Normal" ini- } \\
\text { tially but reread } \\
\text { to suggest } \\
\text { neuropathic }\end{array}$ & \\
\hline $\begin{array}{l}\text { Proband's } \\
\text { brother \#1 }\end{array}$ & 20 & & Absent & Present & & Present & & Neuropathic & \\
\hline $\begin{array}{l}\text { Proband's } \\
\text { brother \#2 }\end{array}$ & 30 & & Absent & & & & Neurogenic & Myopathic & \\
\hline $\begin{array}{l}\text { Proband's } \\
\text { daughter } \\
\text { (confirmed by } \\
\text { genetic testing) }\end{array}$ & $\begin{array}{l}\text { Shoulder and } \\
\text { neck pain, age } \\
30\end{array}$ & & & & & & & & \\
\hline $\begin{array}{l}\text { Proband's niece } \\
\text { (confirmed by } \\
\text { genetic testing) }\end{array}$ & $\begin{array}{l}\text { Shoulder and } \\
\text { neck pain, age } \\
40\end{array}$ & & & & & & & & \\
\hline
\end{tabular}

\section{VCP mutation: Clinical manifestations IBMPFDACHPAS}

Heterogenous

Hereditary inclusion body myopathy

Paget's disease of the bone

Frontotemporal dementia

Familial ALS

CMT 2Y

Hereditary Spastic Paraplegia

Parkinson's Disease

Alzheimer's Disease

Scapuloperoneal syndrome with myopathic and neuropathic features

$\star$ Our family
Multi system proteinopathy (MSP)

FIGURE 5: The expansion of the VCP spectrum.

and her colleagues at the University of Iowa including Dr. Michael Shy, Dr. Andrea Swenson, Dr. Stephen Moore, Dr. Katherine Mathews, Erin Springer, Tiffany Grider and Chelsea Bacon. She would also like to thank her mother, Dr. Veena Uberoi Jerath for her constant support and encouragement.

\section{References}

[1] N. U. Jerath, C. D. Crockett, S. A. Moore et al., "Rare manifestation of a c.290 C>T, p.Gly97Glu VCP mutation," Case Reports in Genetics, vol. 2015, Article ID 239167, 5 pages, 2015.
[2] C. S Clemen, L. Eichinger, and R. Schroder, "Reply: hereditary spastic paraplegia caused by a mutation in the VCP gene VCP: a Jack of all trades in neuro- and myodegeneration?" Brain, vol. 135, no. 12, pp. e224-e224, 2012.

[3] M. A. Gonzalez, S. M. Feely, F. Speziani et al., "A novel mutation in VCP causes Charcot-Marie-Tooth Type 2 disease," Brain, vol. 137, no. 11, pp. 2897-2902, 2014.

[4] J. P. Taylor, "Multisystem proteinopathy," Neurology, vol. 85, pp. 658-660, 2015.

[5] X. Guo, Z. Zhao, H. Shen, B. Qi, N. Li, and J. Hu, "VCP myopathy: a family with unusual clinical manifestations," Muscle \& Nerve, vol. 59, no. 3, pp. 365-369, 2019. 
[6] T. Liewluck, M. Milone, M. L. Mauermann, M. Castro-Couch, J. H. Cerhan, and N. S. Murthy, "A novel VCP mutation underlies scapuloperoneal muscular dystrophy and dropped head syndrome featuring lobulated fibers," Muscle \& Nerve, vol. 50, no. 2, pp. 295-299, 2014.

[7] M. A. Gitcho, J. Strider, D. Carter et al., "VCP mutations causing frontotemporal lobar degeneration disrupt localization of TDP43 and induce cell death," Journal of Biological Chemistry, vol. 284, no. 18, pp. 12384-12398, 2009.

[8] G. D. J. Watts, J. Wymer, M. J. Kovach et al., "Inclusion body myopathy associated with Paget disease of bone and frontotemporal dementia is caused by mutant valosin-containing protein," Nature Genetics, vol. 36, no. 4, pp. 377-381, 2004.

[9] A. Manno, M. Noguchi, J. Fukushi, Y. Motohashi, and A. Kakizuka, "Enhanced ATPase activities as a primary defect of mutant valosin-containing proteins that cause inclusion body myopathy associated with Paget disease of bone and frontotemporal dementia," Genes to Cells, vol. 15, pp. 911-922, 2010.

[10] F. Bartolome, H.-C. Wu, V. S. Burchell et al., "Pathogenic VCP mutations induce mitochondrial uncoupling and reduced ATP levels," Neuron, vol. 78, no. 1, pp. 57-64, 2013.

[11] X. Zhang, L. Gui, X. Zhang et al., "Altered cofactor regulation with disease-associated p97/VCP mutations," Proceedings of the National Academy of Sciences, vol. 112, no. 14, pp. E1705-E1714, 2015.

[12] A. Nalbandian, K. J. Llewellyn, M. Kitazawa et al., “The homozygote VCPR155H/R155H Mouse model exhibits accelerated human VCP-associated disease pathology," PLoS One, vol. 7, no. 9, p. e46308, 2012.

[13] V. E. Kimonis, S. G. Mehta, E. C. Fulchiero et al., "Clinical studies in familial VCP myopathy associated with Paget disease of bone and frontotemporal dementia," American Journal of Medical Genetics Part A, vol. 146A, no. 6, pp. 745-757, 2008.

[14] E. Al-Obeidi, S. Al-Tahan, A. Surampalli et al., "Genotypephenotype study in patients with valosin-containing protein mutations associated with multisystem proteinopathy," Clinical Genetics, vol. 93, no. 1, pp. 119-125, 2018.

[15] T. Zhang, P. Mishra, B. A. Hay, D. Chan, and M. Guo, "Valosincontaining protein $(\mathrm{VCP} / \mathrm{p} 97)$ inhibitors relieve Mitofusindependent mitochondrial defects due to VCP disease mutants," eLife, vol. 6, 2017. 


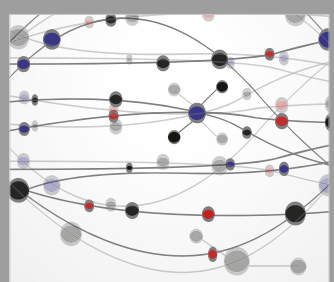

The Scientific World Journal
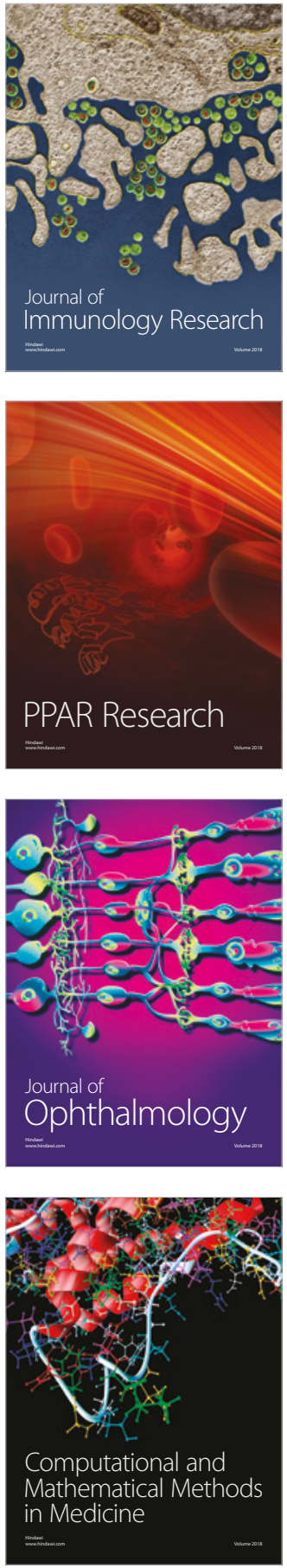

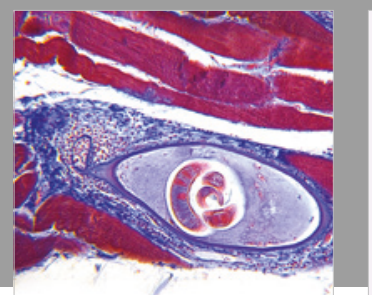

Gastroenterology Research and Practice

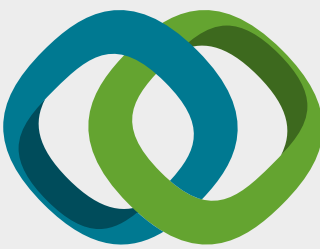

\section{Hindawi}

Submit your manuscripts at

www.hindawi.com
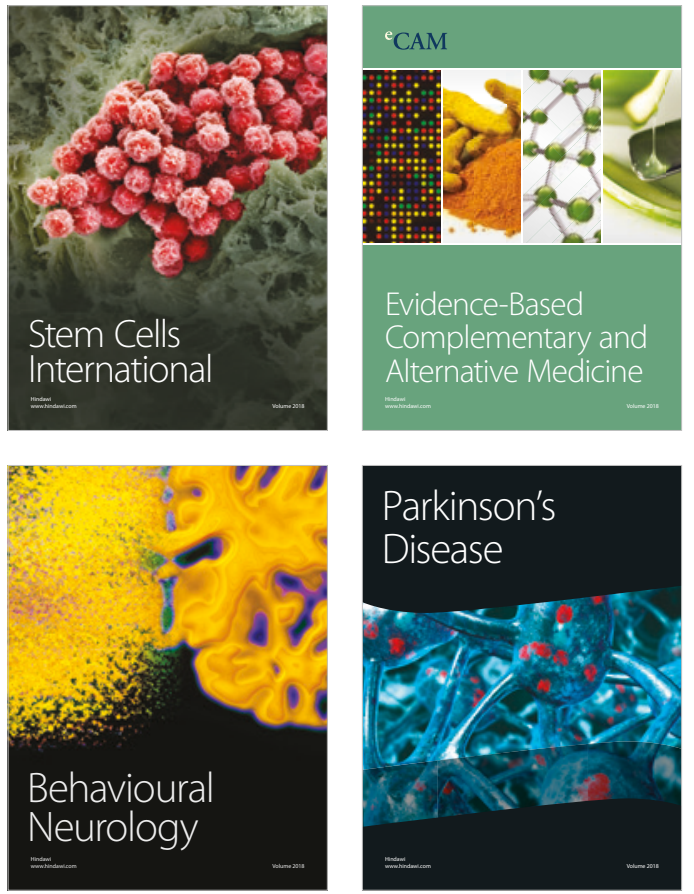

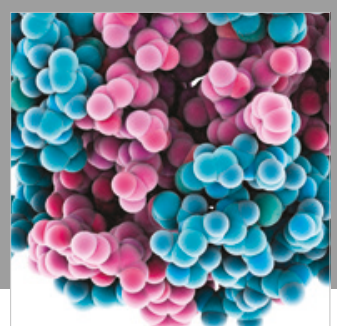

ournal of

Diabetes Research

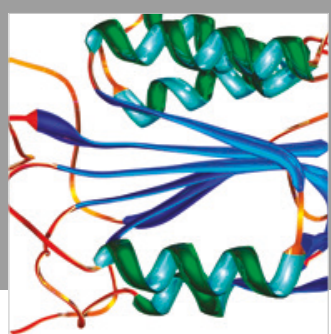

Disease Markers
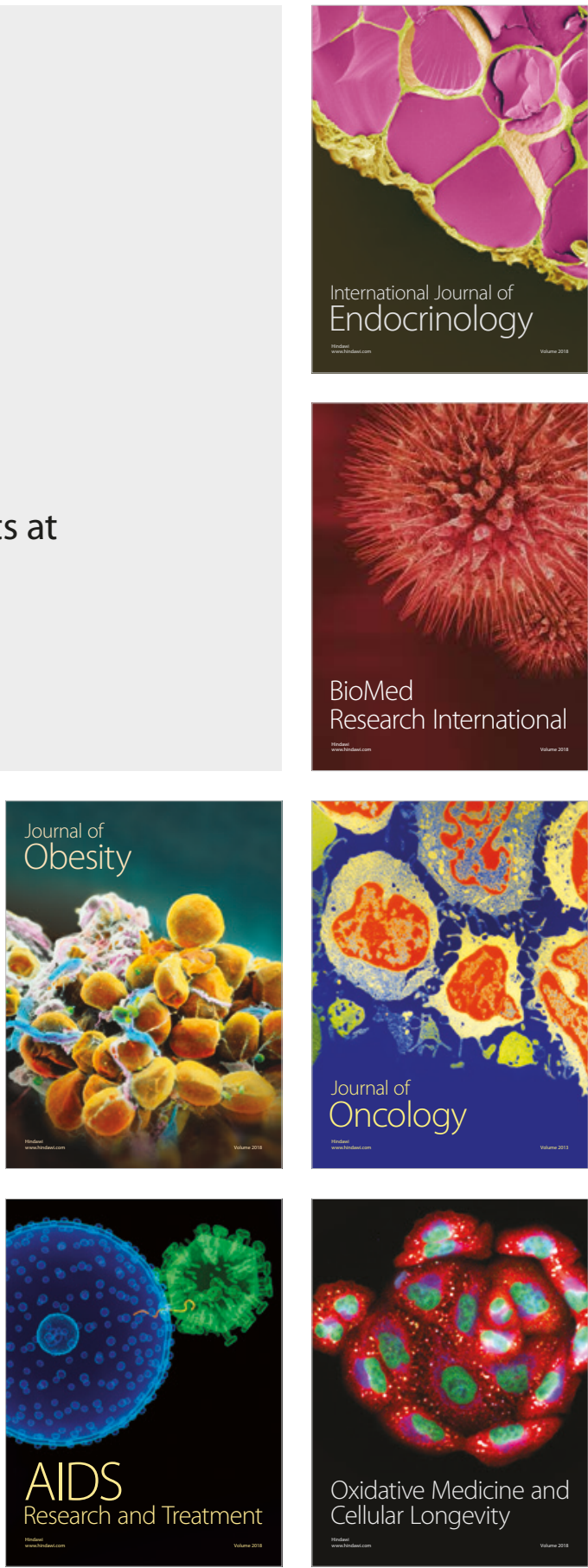